\title{
Theoretical Concepts of Insurance Production *
}

\author{
by Wolfgang Müller **
}

\section{Introduction}

The central problem of this paper may be indicated by an apparently naive question :

"What is the product insurance companies sell, and how is this product generated ?" 1

At first glance, this question may appear trivial. Insurance companies have quite clear ideas on the techniques of insurance underwriting, and besides, there are voluminous textbooks offering detailed descriptions of the subject of insurance. However, the generally accepted concepts and definitions of insurance show some rather disturbing inconsistencies. There are doubtful practical and political implications for insurance industry flowing from the current theoretical understanding of the insurance product and production process. Quite a few of the problems insurers have in increasing degree with their customers and the public, may well be attributed to unclear or even illconceived concepts of the product of insurance.

In the following section of this paper some of the present problems will be pointed out which insurance industry is facing and which may be directly linked to prevailing concepts of insurance theory. In section 3 some major approaches of insurance theory will be critically reviewed. Considerations for an alternative approach to the insurance concept will be put forward in section 4 , and to the insurance production problem in section 5 . In the final section 6 some first theoretical and practical consequences of the alternative approach will be examined.

* I would like to thank Dr. H. Loubergé for helpful comments on an earlier draft of this paper, presented in July 1980 at the IIS Seminar in Paris and in September 1980 at Nottingham University at the Seventh Seminar of the European Group of Risk and Insurance Economists. Of course, the views expressed and any remaining errors are mine.

** Professor of Business Administration and Insurance, University of Frankfurt.

1 In the following analysis only the main product of insurance is considered. It will not be asked whether insurance companies generate by-products and what these may be. 


\section{Problems of insurance production}

\subsection{Explaining the product of insurance}

Insurance has a long tradition of mixed evaluation in the general public and political opinion (see Müller [1978]). Its economic and social importance is undisputed in all market economies. Its technical design and actual performance, however, have been subject to much complaint and criticism, which in turn have led to a remarkable extension of legal constraints, state regulation and control of the insurance market. Although some of these problems may in fact be due to questionable practices in acquisition and claim settlement, it is well known that most of the difficulties with insurance cannot be related to incorrect behavior of insurance companies. Instead, it is insurance itself, this "awkward good", as it has been called (Pfeffer [1956], p. 6), which causes many problems.

Difficulties start right away with the diverse efforts of insurers and insurance theorists to explain what is really involved when a risk is covered by insurance. In textbooks and other writings on insurance (see, e.g., Möller [1962] ; Farny [1965] ; Mehr/Cammack [1976] ; Vaughan/Elliott [1978]) much effort has been spent to develop elaborate and comprehensive definitions of insurance. For example, Pfeffer and Klock ([1974], p. 3) offer the definition :

"Insurance is a device for the reduction of uncertainty of one party, called the insured, through the transfer of particular risks to another party, called the insurer, who offers a restoration, at least in part, of economic losses suffered by the insured."

This characterization of insurance stresses a major aspect which can be found implicitly or explicitly in most other definitions, namely the reduction of risk through some transfer mechanism. In fact, Trowbridge ([1975], p. 1) sees risk transfer to be "at the very heart of the typical insurance arrangement".

While the central concept of risk transfer may be convenient for some purposes of theoretical analysis, because of its high level of abstraction it is neither operational nor suitable for the practical needs of insurance business. In fact, insurance business has never considered it a very convincing argument to explain to customers that the premium is to be paid in exchange for the transfer of risk. Thus, insurance definitions usually provide an explanation of what is actually involved in risk transfer. These operationalizations then either point to the coverage of economic losses by insurance, as Pfeffer and Klock ([1974], p. 3) do, or they describe the transfer as flows of money (Trowbridge [1975], p. 1). Insurance business prefers to emphasize the money transfer of insurance arrangements. Particularly in advertising and sales activities it is quite common to represent the payments in case of loss as the actual primary service rendered by insurance.

However, this operationalization of the transfer mechanism in terms of loss coverage and money payments is not only an inconsistent but also a highly ambiguous 
way of making the insurance product comprehensible and attractive to customers and the general public. It has the direct implication that any insured whose contract is free of claims does not receive a service equivalent to his premium payments ${ }^{2}$. The strong linkage between loss payments and the insurance product may well contribute to the formation of unclear and excessive expectations towards the services of the insurer. It may even induce the conviction on the side of insureds that the principle of equivalence is violated in insurance contracts. This may well be a major cause for the phenomenon of moral hazard which is sometimes all too easily attributed solely to indifference and even dishonesty of the insured (see, e.g., Arrow [1974] ; Greene [1977], p. 9). Generally, there are strong indications that rather often such unclear ideas about the insurance product play an important role in the disturbed attitude towards insurance.

\subsection{Understanding the insurance production process}

The difficulties with the insurance product are, however, only part of the picture. Closely related is the problem of an adequate understanding of the conditions and activities by which insurance is produced. Again, this problem has many practical implications, of which the political and managerial aspects are most important.

a) Entrepreneurial vs. administrative approach

The main issue of the political aspect is whether the production of insurance is an entrepreneurial task or rather an administrative one. The decisive difference between the two philosophies, entrepreneurial vs. administrative, appears to concern the scope of tasks, responsibility, and authority of the management of insurance companies. In the entrepreneurial approach insurance is considered to be a good produced and sold by the company which has, within certain legal constraints, the full rights of disposition over all managerial activities involved. In the administrative approach it is assumed that risk pooling is achieved by a mechanism not subject to managerial decisions. The insurance company has solely to provide the necessary administrative services, like processing of applications and claims, to keep the mechanism functioning. Hence, the rights of disposition of company management extend only over the administrative activities.

Each approach has far-reaching consequences with respect to price setting competence, the justification of profit and its distribution, participation of insured in company affairs, governmental influence on insurance markets and company activities, etc.

These alternative views of insurance production are of a very real nature, not just abstract possibilities. The most striking incident presently, in the Federal Republic of Germany, is the claim by a consumerist group that about 275 billion DM accumulated

2 In order to avoid this implication, in the German literature it is proposed to characterize the insurance product as "insurance protection" (cf. Farny [1965], p. 7) or "latent or acute bearing of peril" (cf. Möller [1962], p. 281). These concepts are, however, very vague and still lack realistic interpretation (cf. Müller [1981]). 
by insurance industry as reserve funds against future obligations, should not be kept within the legal decision authority of insurance company management. This demand is part of an administrative approach to insurance. It is still gaining increasing attention by mass media and politicians and may indeed entail long-term consequences with respect to even stronger state influence on the insurance industry.

The real problem with this controversy are not the 275 billion DM of funds they "belong" to the insureds anyway. Rather it is the highly dubious, inconsistent and partly even irrational arguments on which these demands are grounded - arguments, however, which insurance industry is not in a position to refute convincingly because they are mainly taken from the recognized body of "insurance theory". Thus, the real problem is this theory which consists, in fact, of a highly entangled mixture of ideas and statements of both, the entrepreneurial and the administrative philosophy of insurance plus some additional ingredients. Hence, almost any position, and political and managerial decision may be justified by this theory - it is just a matter of the suitable selection and interpretation of arguments.

b) Managerial problem areas

The managerial problems of insurance production originate from the well-known factum that the insurance product is not a material good but a special kind of service. Hence, the economic conditions and processes of generating this service possess their own properties.

Traditionally, the "standard model" for thinking about production processes is, however, the industrial plant. Many experiences and techniques developed in industry have been transferred, sometimes even prescribed to insurance business. So it is not really surprising that the implementation of those concepts and techniques in insurance business very often yields unsatisfactory results, sometimes causes outright difficulties. This applies, for example, to central parts of the accounting systems, to production and manpower planning.

Just the other side of this same coin is the management of information processing and communication technologies. Insurance companies have implemented computers on a large scale and undoubtedly gained considerable increases in productivity. Again, however, insurance companies are taking over and adapting more or less successfully to their specific requirements concepts and techniques which have been developed on "foreign territory". This time it is the software systems philosophy, the core of computer implementations, which is primarily developed according to the technical and marketing objectives of computer industry. The most prominent case in point is the concept of a highly centralized and integrated information system promulgated by computer industry under the label of Management Information System (MIS). Although the rather narrow limits and sometimes even precarious consequences of MIS software philosophy are known for some years (cf. Müller [1980]), it still is offered to insurance companies as highly efficient software technology. In general, insurance management is learning by the hard way that the introduction of computer information processing technology on the scale and in the task areas considered today is qualitatively different from just setting up faster machinery for rate calculation and book-keeping. More than in most other industries, computers in insurance are rapidly and thoroughly affecting 
whole organizational structures, from individual task specifications and task allocation to formal and informal organizational relations.

Here the real problem is, of course, neither computer industry marketing strategy nor the mere event of organizational change. The real problem is that insurance company management has no suitable means at hand to lead the way in this fundamental change of conditions and processes of insurance production. There is no practical experience to set long-range strategic goals for company development and to evaluate proposed computer information processing with respect to their contributions to these goals. And there exists no suitable theoretical basis to support insurance management in tackling these important tasks. Neither those doubtful product concepts nor present approaches to insurance production are offering effective help for the solution of these problems.

\section{The scope of some major approaches of insurance theory}

After this somewhat critical evaluation of insurance theory from a practical point of view it appears necessary to examine in a more discriminating manner what relevant results existing approaches of insurance theory offer and where their limits are. However this paper is not intended as a survey of insurance concepts, so only the most important general approaches to insurance will be considered. Also the analysis will be highly selective and concentrate on those concepts of each of these major approaches which appear to be characteristic for the respective understanding of insurance production.

\subsection{Insurance law}

Since more than a century the legal sciences have formed insurance concepts through their influence on codified insurance law and on jurisdiction. Thus, many areas of insurance theory and practice today are based on legal concepts and dominated by legalistic thinking.

Apart from its general contractual aspects insurance law serves two main insurance-specific functions. First, insurance law is the means to specify and describe the services or products of the insurer (see, e.g., Klingmüller [1965]; Farny [1975]; Vaughan/Elliott [1978]). The risk underwritten has to be exactly determined with respect to the object insured, admitted perils and loss events as well as to the amount of eventual loss compensation. For this product description everyday language is too imprecise and too ambiguous. Legal norms thus fulfil the same function that technical norms, like ASA-standards, have for the specification of material products. This technical function of insurance law provides the operational basis for insurance product specification.

Secondly, insurance law is instrumental in exercising state supervision and regulation of insurance. Although objectives and concrete measures show considerable variance internationally, the major functions of regulatory law can be seen in the protection of basic interests of insureds, particularly in the guarantee that legitimate 
claims of insureds can be satisfied materially. In order to obtain real security the insured must be able to trust that the economic conditions for meeting his claims are given at any point in time of contract duration. This legal guarantee function is executed in practice by legal constraints imposed on insurance management decisions.

Without doubt, in a pragmatic sense these functions of insurance law are important for insurance companies and their customers alike. A serious problem arises, however, when legalistic perspectives and concepts are used in a much broader way, embracing virtually all aspects and operations of insurance production (see, e.g., Priester [1968] ; Mehr/Cammack [1976] ; Gärtner [1980]). In the perception of such a legal approach insurance is represented as a contract and the insurance company as an institution for underwriting and executing contracts, directed by a set of legal norms. Characteristically, as a starting point for thinking about insurance, the legal approach develops definitions which are supposed to capture the essence of insurance and its product. Numerous efforts of this sort have been made and almost every textbook on insurance starts with its definition.

The legal approach shows two serious weaknesses. Methodologically, the real phenomenon insurance may not be defined but must be described and explained by a theory which can be tested against reality. Essentialistic definitions of insurance are not suited for purposes of theoretical investigation (see Wälder [1971]). Furthermore, the legal approach leaves no room for innovative and efficient problem solving activities of insurance company management. Legal norms are just not designed as instruments for generating solutions to planning, decision making, and organizational tasks.

While the product description and guarantee functions of insurance law are indispensable parts of the insurance production, their overinterpretation in the legal approach tends to conceal rather than to solve some key problems of insurance.

\subsection{Actuarial sciences}

The contribution of the actuarial sciences to insurance can be described quite generally as the provision of models for the determination and estimation of risks, particularly under specific conditions of large collectives of quasi-random events (see, e.g., Braeß [1960] ; Beard/Pentikäinen/Pesonen [1969]; Borch [1974]). A central concept of the actuarial sciences is the statistical law of large numbers. It constitutes the basis for many theoretical analyses and technical operations with respect to risk pooling and premium calculation in several insurance lines.

The useful function of actuarial models is again strongly overinterpreted when used to represent total insurance company operations. This actuarial approach to insurance basically reduces all the relevant aspects of insurance production to probability distributions and stochastic processes related to flows of indemnity payments. A very similar perspective of insurance production is involved in the interpretation of the law of large numbers as the production function of insurance (Allais [1953], p. 286).

Thus in the actuarial approach insurance production is viewed as a strictly mechanical process, representing the insurance product by money payments and 
governed by a simple statistical rule. While this abstraction may be useful for the major function of actuarial models, the forecast of future loss payments of risk pools and the ensuing determination of risk premiums, it definitely fails to recognize the managerial role and its influence on insurance production. Generally, forecasting models are not suitable for the solution of planning and decision problems in business organizations.

\subsection{Economic theory of market equilibrium}

There are several economic approaches to insurance. Among them the most generally accepted and acclaimed theoretical foundation of insurance is the economic theory of market equilibrium (see Arrow [1953], [1964] ; Debreu [1959] ; Borch [1968] ; Eisen [1979]). This approach is, however, largely irrelevant for the questions considered here and will thus be reviewed only as far as is necessary to explain this assessment.

In order to capture risk and processes of risk distribution in market economies, modern economic theory operates with the concept of a certain type of certificates, sometimes called "Arrow certificates". The basic idea is that in a world of uncertain events through the exchange of Arrow certificates different-valued risk positions of market participants may be equalized. Because of their general properties, Arrow certificates have been interpreted as insurance policies (see Borch [1962] ; Kihlstrom/Pauly [1971] ; Eisen [1979], p. 93 ff.). Hence, insurance has come to play a prominent role in economic market theory.

For the purpose of this analysis a very important characteristic of Arrow certificates is their function in a pure market with no production of goods. Accordingly, insurance is to be considered as a mechanism for a particular distribution of goods in a market with uncertainty, but, in market theory, insurance is not a good itself (see Eisen [1980], p. 542). It follows that economic market theory does not provide a product concept of insurance at all. Also the insurance production process, for systematic reasons, is not a subject of investigation for market theory, as Borch [1977] has observed only recently.

From this, two conclusions can be drawn :

- Economic market theory is concerned with general exchange conditions of markets, but not with managerial planning and decision making problems of individual insurance companies.

- Hence, market theory is not directly applicable for the investigation of such managerial problems, including those referring to the product and production of insurance. It follows directly, that it would be inconsistent to use results derived under the specific assumptions of market theory for the purpose of investigating problems of insurance production. This applies, for example, to the results obtained by Marshall [1974] with respect to mutual risk pool organization and by Eisen [1980] with respect to risk premium determination.

If these conclusions appear to be too rigorous it should be remembered that other theories of great importance for the management of individual companies, notably 
management sciences and organization theories, cannot be founded on general economic market and price theory. In order to avoid misunderstandings it should also be pointed out that these conclusions on the general relationships between economic market theory and theories of business administration do not rule out common basic theoretic elements, like decision theory, or the fertility of transferring ideas from one theoretical area to the other. Gaining suggestions is, of course, quite different from systematic foundation.

\subsection{Portfolio theory}

In recent years a number of efforts have been made to apply financial portfolio theory to insurance company decision making. In this approach, which is rooted in the general theory of market equilibrium (see Borch [1979] ; Hirchleifer/Riley [1979]), the insurance company is represented as a levered investment operation, borrowing funds by issuing risky obligations and investing part of these funds in securities (see, e.g., Haugen/Kronke [1970] ; Biger/Kahane [1978] ; Doherty [1980]). Insurance consists in the management of a portfolio of underwriting and investment positions. The theoretical basis for the analysis and evaluation of portfolio management decisions is the capital assets pricing model. It was originally developed for financial investment decisions (see Sharpe [1964] ; Lintner [1965]) and is now applied to the insurance situation. This model links individual investment decisions according to profit and risk criteria with optimality conditions of overall financial markets. Because of this general economic relationship and because it permits consideration of all financial operations of insurance companies, the portfolio theory approach has been used to critically reevaluate a number of actuarial results, like risk loading of insurance rates (Kahane [1979]) and determination of insurance capacity (Doherty [1980]).

Although the portfolio theory approach may indeed offer an extended scope of insurance problems, in some major characteristics it bears similarities with the actuarial approach discussed above. Most important, the total of insurance activities is again reduced just to decisions on financial operations. The insurance product and production process are based only on money payments and leave no room for the recognition and solution of the type of problems most pressing for todays insurance management but fails to capture the complex diversity of factors influencing insurance decision making.

\subsection{Management sciences}

Since the perspective of this analysis is product and production processes of the insurance company, it should be expected that business administration and management theories would provide appropriate concepts and approaches to these areas. In fact, the management sciences have contributed quite heavily to management techniques of insurance companies, particularly in areas like planning, marketing, and organizational leadership. With one notable exception (cf. Farny [1969], [1977]) there have, however, been no developments of theoretical foundations taking into consideration the specific characteristics of insurance production. 
Of course, insurance company management is not totally different from management tasks in other industries, and thus there are many parts of management theory which may, in principle, be applied in insurance. This is not true, however, of the insurance production processes. While existing management theory of production is concerned with material products, insurance generates a specific immaterial product. This is why the transfer of production theory to insurance often has unsatisfactory, even doubtful consequences. For the same reason, the only management science approach offering a theoretical foundation of insurance production, already alluded to above, has only limited capacity to solve the problems mentioned here. Because it is based on traditional production theory (cf. Gutenberg [1973]) it cannot capture the characteristics of insurance product and production process pointed out (see also Müller [1981]).

\subsection{Summary}

Admittedly this presentation of theoretical approaches to insurance production may be somewhat incomplete and may not give due credit to some fine points of the work considered. Nevertheless, from the principal perspective assumed here, a few general conclusions may be drawn :

- There is no systematic theory of insurance. Rather there is a rich choice of separate theoretical approaches, sometimes loosely coupled, sometimes inconsistent, but mostly not related together. Each of these approaches and their major concepts are designed for specific purposes and most of them are concerned with only limited aspects of insurance company activities. Despite their limited scopes and relevances, each of the approaches has been claimed to represent a general model of insurance.

- None of the approaches offers a satisfactory solution to the product concept and production process of insurance. For economic theory of market equilibrium the insurance production problem does not exist. The other approaches more or less explicitly support a product concept based on money payments. With respect to the production processes only the management science approach provides limited results. None of the approaches offers a profound basis to tackle the conceptual, political and managerial problems of present insurance practice, as outlined in the second section of this paper.

In contrast to the present position of economic market theory, the insurance production process is considered here as a relevant and important theoretical problem. It is viewed, however, not from the general market perspective but from the perspective of insurance company management. Risk pooling is not an automatism, rather its outcome is dependent upon management decision making. This means, the quality of insurance products and the efficiency of their production cannot be better than the quality and efficiency of insurance management activities.

In the following parts of this paper some ideas are presented on a new direction to attack these theoretical and practical problems of insurance. 


\section{Information approach to insurance}

\subsection{Information, risk and insurance in decision making}

Probably the most widely accepted paradigm in economic theory today is the decision making situation. This paradigm is also applied in most of the approaches reviewed above and may therefore be used as a common basis for further investigation of the insurance problem.

Because of his limited cognitive capacity man has always to cope with uncertain knowledge about future events and consequences of his decisions. No matter, whether in private affairs or in business, whenever man decides on a course of action he bears a risk because he does not command perfect information on the present and future conditions of his decisions. Risk, therefore, generally designates the situation of decision making under incomplete information ${ }^{3}$.

A decision situation can be described as the choice, according to the objectives of the decision maker, of one among several alternative courses of action. The major conceptual elements of a decision situation are : courses of action (a), their outcomes $(r)$, given different states of the world $(s)$, each of which has a probability of occurrence $(p)$ (see, e.g., Bamberg/Coenenberg [1974]).

These elements may be arranged in the decision matrix as follows :

\begin{tabular}{|c|ccccccc|}
\hline & $s_{1}$ & $\cdot$ & $\cdot$ & $\cdot$ & $\cdot$ & $\cdot$ & $s_{n}$ \\
& $p_{1}$ & $\cdot$ & $\cdot$ & $\cdot$ & $\cdot$ & $\cdot$ & $p_{n}$ \\
\hline$a_{1}$ & $r_{11}$ & $\cdot$ & $\cdot$ & $\cdot$ & $\cdot$ & $\cdot$ & $r_{1 n}$ \\
$\cdot$ & $\cdot$ & $\cdot$ & $\cdot$ & $\cdot$ & $\cdot$ & $\cdot$ & $\cdot$ \\
$\cdot$ & $\cdot$ & $\cdot$ & $\cdot$ & $\cdot$ & $\cdot$ & $\cdot$ & $\cdot$ \\
$\cdot$ & $\cdot$ & $\cdot$ & $\cdot$ & $\cdot$ & $\cdot$ & $\cdot$ & $\cdot$ \\
$a_{m}$ & $r_{m 1}$ & $\cdot$ & $\cdot$ & $\cdot$ & $\cdot$ & $\cdot$ & $r_{m n}$ \\
\hline
\end{tabular}

In decision theory usually the-assumption is made that possible alternative actions, outcomes and states of the world are known to the decision maker and that he is required to assign subjective probabilities of occurrence to the states of the world. Thus information acquisition activities of the decision maker are relevant only for the determination of probabilities (see Marschak/Radner [1972]). Risk, as characterized above, refers to incomplete information with respect to probabilities. If these rather strict assumptions are relaxed, as has been the case in recent developments in decision theory (see Laux [1979]), then information requirements may exist also with respect to the other elements of the decision matrix, i.e., actions, outcomes, and states. This also involves broadening the concepts of information and risk.

3 This general characterization of risk in decision situations should be strictly distinguished from the method of measuring risk, which is not considered here. 
In many decision situations insurance serves an important function : By signing an insurance contract the decision maker does reduce the risk related to a decision situation. This is actually realized by enabling the decision maker to foresee with certainty, according to the terms of the insurance contract, some of the future outcomes of the decision. Through insurance the decision maker reaches an improved state of information. In other words, the perceived information deficit of the decision maker is reduced by means of obtaining insurance.

\subsection{Information provision by insurance}

If this interpretation of insurance is to make sense, it has to be explained in which way the information deficit in decision making situations can be reduced by insurance. After all, insurers are neither omniscient nor clairvoyant. On the contrary, typically they will have even less information on a specific decision situation of a customer than the customer himself ${ }^{4}$.

For that reason the insurer cannot reduce the information deficit with respect to the question if and to what extent a loss event will affect the decision maker. Yet the matter is different with respect to the consequences of a loss event. The insurer is indeed in the position to guarantee to the decision maker that a specific, agreed-upon state of an insured object will also exist in the future. The insurer can meet such an obligation even in case of a specific event which changes the agreed state of the object. In this case the insurer has to take care of the restoration of the agreed state.

In terms of the decision matrix buying insurance for a specific course of action, say $a^{*}$, has the effect that for the decision maker there will be only one outcome : the outcome $r^{*}$ agreed with and guaranteed by the insurer. This outcome will be realized for the decision maker, no matter which of the admitted states of the world $s_{1}, \ldots, s_{n}$ (loss events) will happen and what effect they will have on the state of the insured object.

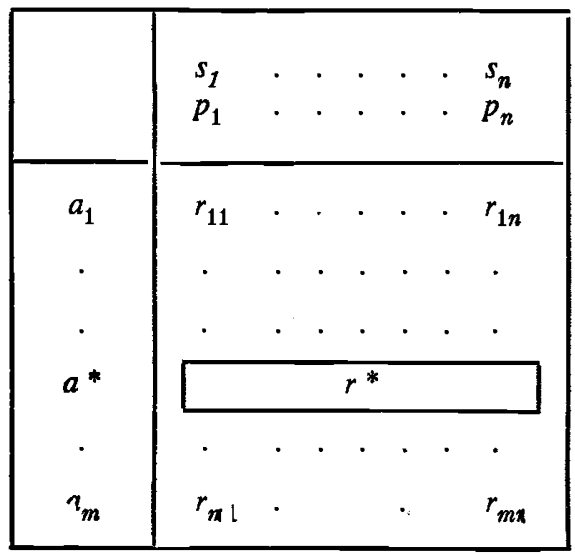

4 This is a central problem of moral hazard; see Hirshleifer/Riley [1979], p. 1391. 
Theoretically, this effect of insurance on the decision situation may be interpreted in various ways. In a strict sense, it means that the decision maker obtains complete information, i.e., certainty $(p=1)$, about a specific outcome for the relevant course of action ${ }^{5}$. For it the decision matrix is collapsed to a vector value $r^{*}$. In a broader sense, admitting incomplete information also for states and outcomes, the insurance product may be interpreted to relieve the decision maker from obtaining information on possible states of the world and outcomes. He need not know nor care for them because of the insurance guarantee for one specific outcome, i.e., one specific state of the insured object.

The argument may be exemplified by a simple case of fire insurance. The decision maker planning and deciding on the future usage of a building principally faces a risk situation. For example, he has an information deficit with respect to a potential fire loss and its consequences. To cope with the fire risk, there are several alternative courses of action available to the decision maker, e.g.,

- measures of fire prevention,

- building up of financial reserves, or

- purchase of fire insurance.

Choosing the last alternative means in principle that the decision maker no longer has an information deficit with respect to the future state of the building, at least within the limits of the specifications of the insurance contract and the ruin probability of the insurer. Should a fire loss occur, the insurer will meet his guarantee of state by arranging for the reconstruction of the building. Hence, the agreed state is maintained in spite of the fire loss.

After these considerations and explanations it is possible to identify the product the insurer provides when signing an insurance contract :

The insurer does deliver to the decision maker certain types of information which reduce his information deficit and enable him to form more reliable expectations about the future state of the insured object.

This basic thesis will be analyzed now with respect to some of its conditions and consequences.

\subsection{Properties of information concept of insurance}

First of all, additional specification is necessary with respect to the information the insurer provides as his product. Information is a widely used term in everyday language as well as in several scientific disciplines and in many cases it does not convey a precise meaning ${ }^{6}$.

5 Referring to "complete information" and "certainty" involves some simplification, neglecting possible problems of interpretation of insurance information and the positive probability of ruin of the insurer.

6 The theoretical foundations of the information concept used here are developed in Müller/Eckert [1978]. 
On the other hand, the information products offered by insurance companies are not one single, standardized set, but vary with respect to scope, interpretation, and individual design. Therefore the information products of insurance may not be enumerated item by item, and any effort of systematic classification may be as hopeless a venture as the efforts have been to detect a logic in types of insurance (see, e.g., Hax [1965]).

Nevertheless some characteristic properties of insurance information products may be identified, distinguishing them from other types of information :

Range: The range of possible insurance information products has been indicated already above in the context of decision logic. Of the major elements of the decision situation, insurance information may at least relate to the probabilities of entry, given specific states of the world, outcomes and actions. On the maximum side, the insurer may provide information also on possible future states of the world and on possible outcomes of actions.

Time dimension: Insurance information always involves guarantees for still unknown states of objects, usually ocurring in the future. In this sense insurance provides only prognostic information. This product is delivered at the beginning of an insurance contract and is maintained for its duration.

Binding force: Insurance information is distinguished from other forecasting information, like weather forecasts, by its legally binding character. The buyer (i.e., decision maker or insured) can trust and, if necessary, enforce that the guarantee of state will be met by the insurer.

Operationalization: The type, contents, and interpretation of insurance information is contained in the insurance contract, generally complemented by insurance codes and jurisdiction. These documents thus provide the operational basis for identification of the insurance information product in every single case. A major function of insurance law is the precise formulation and, if necessary, interpretation of the contractual representation of insurance information.

These characteristic properties are sufficient to distinguish the information products of insurance from all other types of information and also to determine operationally the real insurance products.

For the sake of simplicity it was argued so far that the insurer meets his guarantee of state in the case of loss by restoring the agreed state of the insured object. This implies a restoration in kind which was common in early forms of mutual insurance, but with very few exceptions is not found today. It would even be impossible for some important lines of insurance. However, the central statement that the product of insurance is information provided to the insured does not at all depend on the mode of restoration. It is only a matter of contractual agreement to express the guarantee of state by the insurer alternatively, say in terms of monetary equivalents. By this way it is possible to account for the insurance of those objects for which the insurer cannot guarantee a certain state from the very beginning, like life and health of persons or unique objects. 
An important consequence of the information concept is the status of loss payments. It was shown earlier that the usual representation of loss payments as the very insurance service is one of the major problems of current insurance theory and practice. As a consequence of the information concept of insurance, loss payments no longer cause this confusion. In order to meet the guarantee of state for the insured object, the insurer has to restore the object state or to make equivalent payments, if a loss event has occurred. It follows that loss payments are not the product or service of the insurer not even part of it. Rather they are, if a loss event renders them due, a part of the production process of the insurer and hence they have the status of production cost. The information the decision maker buys from an insurance company derives its value solely from its utility to reduce the information deficit in a risky decision situation. Theoretically it is not dependent on the occurrence of loss events and loss payments.

\section{A model of the Information production process}

From the close relationship between product concept and understanding of the production process now follows the task to develop a theoretical model of insurance production which is consistent with the product concept introduced in the preceding section. Stated more concretely: Given the information concept of the insurance product it should be shown now how this product is generated by insurance companies. Such an insurance production model is not only a useful extension of the basis laid out by the product concept. It is also a first test of the theoretical power and explanatory potential of the information concept of insurance.

\subsection{Specific properties of the information production process}

Insurance being a particular type of information, the analysis is first carried out on the general level of information production. It is later transformed into the more specific conditions of insurance production. Easiest access to the specific properties of information production is probably gained by a comparison with the production process of material goods.

A common starting point for both, the material and the information production process, is the combinatorial input-output-model. In order to generate a particular output, a set of particular input factors is required together with some particular procedures according to which the input factors are combined. While this input-outputmodel is assumed to hold also for information production, significant differences have to be observed for the types of input factors and the properties of the combinatorial procedures of information production. In order to produce material goods, for each unit certain amounts of raw material and parts are used up as inputs. They become integral constituents of the product. Additional input factors usually are human labor force, machine capacity, and energy. Combinatorial procedures for these input factors 
are mainly technical specifications, processes, and methods. In addition, economic efficiency criteria are considered.

In information production, on the other hand, in many cases only a single human being is necessary to generate a particular output. In some areas, like insurance companies, today man is often assisted or even substituted by machines, particularly electronic computers, in the processing and production of information. It would be too simple and superficial, however, to treat man or machine as unitary factor of information production which cannot be further investigated. It is well known that the actual performance and output of computers is heavily dependent on the programs, i.e., processing rules, and the data, i.e. prior information inputs, fed into the machine. The machine itself, in a technical sense, provides only the processing capacity through which prior information inputs and processing rules are given the operative basis for the purpose of generating information output. Thus the machine can be considered as the processing agent which supports the combination of particular types of prior informations according to particular rules governing the processing of the prior information.

It has been shown by the theory of human problem solving (see Newell/Simon [1972]) that it is very fruitful to use this model of machine information processing also as a way of thinking about human information generation. This is not meant to treat man as a machine. But it is fairly obvious that man has to learn processing rules, particularly the rules of language, logic and mathematics, and that he has to possess or obtain specific knowledge, particularly about a question to be answered or a problem to be solved, before he or she can produce a particular information output, i.e., the required answer or solution.

From these considerations a simple but quite instructive model of the information production process may be constructed. It contains as inputs prior informations and capacity of human and machine processing agents. These inputs are combined by information processing rules in order to yield desired information outputs.

The most conspicuous distinction of this model as compared with the material production model is the fact that neither the input of prior informations and processing rules nor the final information output, the product, represent any amount of material value worth mentioning. For their representation pieces of paper, magnetic tape, or the human brain are sufficient. This is what is often meant when information is characterized as an immaterial good. Of course, this does not imply that obtaining prior information, processing rules or even information output is also close to costless. In fact, it depends : if they have to be purchased or produced first, these informations may be quite costly. If, however, they are already available in some storage-place, like a memory or a file, then another interesting property of information production becomes effective : Information and processing rules available can be easily copied and used for any additional information production process as often as necessary without perishing or even depreciating. Therefore, also the incremental cost of multiple usage of available information and rules may be very small.

To move the model somewhat closer to reality, it should be completed with one important additional aspect. Because of their qualitative and quantitative capacity 
limits, neither human nor machine processing agents are able to perform as individuals those information production tasks required by the typical business firm, including insurance companies. Consequently, tasks have to be divided and several, quite often numerous human and machine processing agents are coupled together in order to perform specialized subtasks of information production. This refers, of course, to the formation of business organizations as the frequent and important means to realize voluminous and highly complex information production processes.

This realistic extension of the information production model shows that for the purpose of this analysis it is not sufficient to investigate the structure of individual information production processes. In addition, it is necessary to recognize and to understand the particular properties related with organizational information production. In general terms this involves capturing the organizational measures of task division, specialization, and coordination through communication, delegation and informal ways of influencing organization members. These organizational measures are governing the multitude of information collection, planning, and decision making processes carried out by individual information processing agents.

Summing up, the model developed here for the representation of information production processes consists of two parts :

- On the level of individual information production, prior information, capacity of processing agents, and processing rules have been specified as factors of the inputoutput-process determining information products. Also, some specific properties of this basic production process have been identified.

- On the aggregate level of organizational information production, which corresponds more closely to business reality, some major cornerstones have been pointed out, indicating how the elements of individual information production are tied together and subjected to specific organizational measures in order to serve the common goal of information production.

This basic model of information production obviously offers only a very general outline for the investigation of highly complex phenomena. Nevertheless, this appears to be sufficient to show that the information concept of insurance opens up a fruitful direction of investigation also of the insurance production process. This general model of information production provides the higher-level theory which will be applied to insurance production in the following section of this paper. In addition this model shows from which other existing theories support may be expected for the further refinement of the insurance production approach presented here. This applies most directly to Simon's theory of organizational decision making (cf. Simon [1976]) and related work (e.g., Cyert/March [1963] ; Simon [1979]) as well as to recent developments in MIS research (e.g., Ives/Hamilton/Davis [1980].

These theoretical approaches do not offer ready-made solutions to the problems of organizational insurance production, but almost certainly they provide a considerable reservoir of useful theoretical results which have not yet been exploited for the investigation and efficient design of insurance organizations. 


\subsection{Application to insurance production}

From the general model of information production a specific model can be developed now of the insurance company as an organized network of specialized and coordinated human and machine processing agents. The particulars of insurance production on the individual level derive to a large extent from the specific types of information required. For example, before an insurance contract can be underwritten several types of information have to be available :

(1) Precise informations on the risk covered and the conditions of coverage have to be produced, i.e., the informations on the guarantee of state provided to the customer. This requires specific prior informations on the structure and behavior of the object concerned, on relevant perils, patterns of damage, modes of loss payments calculation, etc. In addition, specific information processing rules have to be developed or selected, especially rules of legal interpretation, which are used to construct the insurance information "package" : the specific contract.

(2) Informations on an acceptable price have to be produced. This demands prior informations on risk premium, administrative, sales and other costs, and possibly the competitive situation on the market. Risk premium information in turn has to be produced according to particular rules, especially by actuarial forecasting models. Similarly, the other cost components of the price rely on a large number of processing rules and prior informations accumulated in the cost accounting system.

These chains of closely interrelated information production and communication activities could be easily extended to include also the specific operations of claim settlements, capital investments, marketing, loss prevention services, risk pool structuring, reinsurance, etc. In general, these examples demonstrate that for each specific task in insurance production particular types of prior information, processing rules, and capacity of processing agents are required. Resulting task solutions are communicated and used as prior information inputs to other tasks until the final products are completed : information in the form of general provisions and specific contractual agreements with the customer.

Interpreting the aggregate organizational level of insurance production is fairly straight-forward. It means arrangement of the large number of individual information production tasks according to some specialization criteria, like functional specialization : legal, actuarial, sales, finance, and administrative departments. It involves also introduction of coordination mechanisms, like a hierarchy of decision authority and formal communication relations between processing agents. As pointed out above, particularly this organization level of insurance production requires much more detailed analysis and may draw on a useful body of relevant theories. The point to be made here should be clear, however : Insurance production is not just a matter of individual tasks in information production, like calculation of risk premiums or capital investment decisions. Rather, it is the result of the organized effort on numerous individual input-output processes. 


\section{Some theoretical and practical implications}

The presentation so far has been deliberately confined to description and explanation of the insurance product and production process in order to expound the information concept proposed here. An additional highly important purpose of such an investigation is the development of normative principles and techniques providing support for the efficient design of insurance products and production processes. Neither the input-output processes described above nor their organizational arrangements have just one way of being realized in practical insurance production. They are, instead, subject to decisions which have to choose among possible design alternatives in order to achieve the highest attainment of individual and organizational objectives. Therefore, decisions have to be made with respect to the selection and efficient usage of the elements of individual information production processes as well as the organizational procedures for their joint efforts. Only if both areas are considered, efficient solutions can be found for insurance production. This involves, e.g., decision making on corporate policies and operative procedures for such basic fields as product design, risk portfolio composition, marketing, finance, information systems, and organizational structure. This is, in its whole scope, the subject area of normative insurance theory and, of course, insurance practice.

It is not the purpose of this analysis to propose recommendations for specific decision problems of insurance production. However, some general problem areas can be readily inferred from the information production model. Theory and practice should see their primary tasks in :

- particular attention for the specific conditions of information production ;

- systematic determination of prior information needs, which is closely related to the information system design problem;

- development and adaptation of information processing rules, i.e., planning and decision procedures for all areas of insurance production ;

- recognition of the fundamental function the machine, especially the computer, nowadays has as information processing agent ;

- development of specific organizational structures and procedures; and

- last, but not least, design of training programs for organizational leadership and professional task performance of organization members.

On the other hand, the information approach provides no justification for the traditional emphasis of theory and practice on legal and actuarial problems of insurance. It it not difficult to see, however, that all approaches reviewed above, which are concerned with insurance production, principally are offering important contributions to the insurance production process. Thus the question of further investigation should be not, whether the legal, actuarial, portfolio, and management theories are relevant, but rather to what extent they do in fact provide useful results for insurance production. 
Finally, there is no indication that any part of the insurance production would work automatically or is the result of pure random processes, as might be inferred from an overinterpretation of the concepts of risk pooling and the law of large numbers. Similarly it appears not possible to draw a clear line to distinguish between risk pooling and administrative tasks of insurance production. The numerous tasks of information processing and their organizational structuring are highly interrelated, and decisions in one area will always affect the other areas and hence the total result of insurance production. Therefore, the scope of authority of insurance company management is not the real difference between the entrepreneurial and administrative philosophy of insurance. Rather, it is the political decision whether insurance is to be produced in economic enterprises in a competitive market or administered by state agencies according to precise regulations. If entrepreneurial philosophy is chosen, the insurance company management should be given sufficient freedom for efficient insurance production decisions. Insurance management, on its part, should fully accept the consequences and responsibilities of its entrepreneurial role.

\section{REFERENCES}

ALLAIS, M. [1953] : “L'extension des théories de l'équilibre économique général et du rendement social au cas du risque", Econometrica, 21 (April 1953), 269-290.

ARROW, K. J. [1953] : "Le rôle des valeurs boursières pour la répartition la meilleure des risques", Colloques Internationaux du Centre National de la Recherche Scientifique, Paris, vol. XL, 41-48.

ARROW, K. J. [1964] : "The role of securities in the optimal allocation of risk-bearing", Review of Economic Studies, 31 (April 1964), 91-96.

ARROW, K. J. [1974] : “Insurance, risk, and resource allocation", in Essays in the Theory of Risk-Bearing, North-Holland, Amsterdam, 134-143.

BEARD, R. E., PENTIKÄINEN, T., and PESONEN, E. [1969]: Risk Theory - The Stochastic Basis of Insurance, Chapman and Hall, London.

BAMBERG, G., and COENENBERG, A. G. [1974] : Betriebswirtschaftliche Entscheidungslehre, Vahlen, Münich.

BIGER, N., and KAHANE, Y. [1978] : “ Risk considerations in insurance ratemaking ", The Journal of Risk and Insurance, 45 (March 1978), 121-132.

BORCH, K. [1962] : "Equilibrium in a reinsurance market", Econometrica, 30 (July 1962), 424-444 ; reprinted in Borch [1974], 141-164.

BORCH, K. [1968] : “Economic equilibrium under uncertainty", International Economic Review, 9 (October 1968), 339-347.

BORCH, K. [1974] : The Mathematical Theory of Insurance, Lexington Books, Lexington (Mass.).

BORCH, K. [1977] : "Some problems in the economic theory of insurance", Newsletter (Geneva Group), 5 (June 1977), 1-11.

BORCH, K. [1979]: "Ökonomische Theorie der Unsicherheit", in Handwörterbuch der mathematischen Wirtschaftswissenschaften, R. Selten (Ed.), Gabler, Wiesbaden, Vol. I, 281-288.

BRAESS, P. [1960] : Versicherung und Risiko, Gabler, Wiesbaden. 
CYERT, R. M., and MARCH, J. G. [1963] : A Behavioral Theory of the Firm, Prenctice Hall, Englewood Cliffs (New Jersey).

DEBREU, G. [1959] : Theory of Value, Wiley, New York.

DOHERTY, N. A. [1980] : "A portfolio theory of insurance capacity", The Journal of Risk and Insurance, 47 (September 1980), 405-420.

EISEN, R. [1979] : Theorie des Versicherungsgleichgewichts, Duncker \& Humblot, Berlin.

EISEN, R. [1980] : " Das Áquivalenz-Prinzip in der Versicherung - Unterschiedliche Folgerungen aus verschiedenen Interpretationen", Zeitschrift fïr die gesamte Versicherungswissenschaft, 69 (4/1980), 529-556. Original English version: "Equilibrium in riskbearing: Different implications of alternative interpretations", The Geneva Papers on Risk and Insurance, 11 (January 1979), 14-33.

FARNY, D. [1965] : Produktions- und Kostentheorie der Versicherung, Verlag Versicherungswirtschaft, Karlsruhe.

FARNY, D. [1969] : "Grundfragen einer theoretischen Versicherungsbetriebslehre", in Wirtschaft und Recht der Versicherung - Festschrift für Paul Braess, D. Farny (Ed.), Verlag Versicherungswirtschaft, Karlsruhe, 27-72.

FARNY, D. [1975] : “AVB unter dem Gesichtspunkt der Produktbeschreibung ”, Zeitschrift für die gesamte Versicherungswissenschaft, 64 (2/3-1975), 169-184.

FARNY, D. [1977] : “Ansätze einer betriebswirtschaftlichen Theorie des Versicherungsunternehmens", The Geneva Papers on Risk and Insurance, 5 (February 1977), 9-21.

GÄRTNER, R. [1980] : Privatversicherungsrecht, Lüchterhand, Darmstadt, 2nd ed.

GREENE, M. R. [1977] : Risk and Insurance, South-Western, Cincinnati (Ohio).

GUTENBERG, E. [1973] : Grundlagen der Betriebswirtschaftslehre - Band I: Die Produktion, Springer Verlag, Berlin.

HAUGEN, R. A., and KRONKE, C. O. [1970] : "A portfolio approach to optimizing the structure of capital claims and assets of a stock insurance company", The Journal of Risk and Insurance, 37 (March 1970), 41-48.

HAX, K. [1964] : Grundlagen des Versicherungswesens, Gabler, Wiesbaden.

HIRSHLEIFER, J., and RILEY, J. G. [1979] : " The analytics of uncertainty and information - An expository survey", Journal of Economic Literature, 17 (December 1979), 1375-1421.

IVES, B., HAMILTON, S., and DAVIS, G. B. [1980] : "A framework for research in computer-based management information systems", Management Science, 26 (9/1980), 910-934.

KAHANE, Y. [1979] : " Risk measurement, portfolio optimization, and insurance rates under capital market equilibrium", in New Frontiers in Insurance: Theory and Practice, Y. Kahane (Ed.), Papyrus, Tel-Aviv, 107-122.

KIHLSTROM, R., and PAULY, M. [1971] : " The role of insurance in the allocation or risk", American Economic Review, 61 (May 1971), 371-379.

KLINGMULLER, E. [1965] : “Zum urheberrechtlichen Schutz neuer Versicherungsbedingungen", in Festschrift für H. C. Nipperdey, R. Dietz and H. Hübner (Eds.), Beck, Munich, 471-488.

LAUX, H. [1979] : Der Einsatz von Entscheidungsgremien: Grundprobleme der Organisationslehre in entscheidungstheoretischer Sicht, Springer, Berlin.

LINTNER, J. [1965] : "The valuation of risk assets and the selection of risky investments in stock portfolios and capital budgets", Review of Economics and Statistics, 47 (February 1965), 13-37.

MAG, W. [1977]2: Entscheidung und Information, Vahlen, München.

MARSCHAK, J., and RADNER, R. [1972] : Economic Theory of Teams, Yale University Press, New Haven (Connecticut). 
MARSHALL, J. M. [1974] : "Insurance theory - Reserves versus mutuality", Economic Inquiry, 84 (December 1974), 476-492.

MEHR, R. I., and CAMMACK, R. [1976] : Principles of Insurance, Irwin, Homewood (Illinois).

MÖLLER, H. [1962] : "Moderne Theorien zum Begriff der Versicherung und des Versicherungsvertrages", Zeitschrift für die gesamte Versicherungswissenschaft, 51 (3/1962), 269-289.

MÚLLER, W. [1978] : "Das Image der Versicherung in der Öffentlichkeit", Die Versicherungsrundschau, 33 (Juni 1978), 180-189.

MÚLLER, W. [1981] : "Das Produkt der Versicherung", in Geld und Versicherung Analysen, Thesen, Perspektiven im Spannungsfeld liberaler Theorie, Festgabe für Wilhelm Seuss, M. Jung, R. R. Lucius and W. G. Seifert (Eds.), Verlag Versicherungswirtschaft, Karlsruhe, $155-171$.

MULLER, W., and ECKERT, J. [1978] : "Informationsproduktion und Entscheidungsprozess", in Neuere Entwicklungen in den Wirtschaftswissenschaften - Verhandlungen auf der Arbeitstagung des Vereins für Sozialpolitik, Duncker \& Humblot, Berlin, 455-478.

NEWELL, A., and SIMON, H. A. [1972] : Human Problem Solving, Prenctice Hall, Englewood Cliffs (New Jersey).

PFEFFER, I. [1956] : Insurance and Economic Theory, Irwin, Homewood (Illinois).

PFEFFER, I., and KLOCK, D. R. [1974] : Perspectives on Insurance, Prenctice Hall, Englewood Cliffs (New Jersey).

PRIESTER, H.J. [1968] : Nachahmungsschutz für Dienstleistungsmodelle, Verlag Versicherungswirtschaft, Karlsruhe.

SHARPE, W. F. [1964] : "Capital asset prices : A theory of market equilibrium under conditions of risk", The Journal of Finance, 19 (September 1964), 425-442.

SIMON, H. A. [1976] : Administrative Behavior - A Study of Decision-Making Processes in Administrative Organization, Mac Millan, New York, 3rd ed.

SIMON, H. A. [1979] : "Rational decision-making in business organizations", American Economic Review, 69 (September 1979), 493-513.

TROWBRIDGE, C. L. [1975] : "Insurance as a transfer mechanism", The Journal of Risk and Insurance, 42 (March 1975), 1-15.

VAUGHAN, E., and ELLIOTT, C. M. [1978] : Fundamentals of Risk and Insurance, Wiley, New York, 2nd ed.

WÄLDER, J. [1971] : Uber das Wesen der Versicherung - Ein methodischer Beitrag zur Diskussion um den Versicherungsbegriff, Duncker \& Humblot, Berlin. 